\title{
LA CRISIS DE LOS ROBOTS SE DEBE A LA CRISIS DE LOS HOMBRES
}

\section{THE CRISIS OF THE ROBOTS IS DUE TO THE CRISIS OF MEN}

Beatriz Peña Acuña: Universidad San Antonio. Murcia (España) beatriz-pa@gmail.com

\section{CURRÍCULUM VITAE}

Licenciada en Filología, Diplomada en Humanidades y Periodista. Profesora de "Observación sistemática y análisis de contextos" en Magisterio Infantil, "Trabajo fin de Grado" en Turismo y "Comunicación interna" a posgrados. Profesora del Cuerpo de Tutores de la Universidad Católica San Antonio. Ha participado en diversos congresos internacionales de innovación educativa como International Conference of Education and Innovation e International Technology, Education and Development Conference con varias ponencias en inglés y ha publicado artículos concernientes a la educación en vasrias revistas científicas. Ha publicado material para docentes de Secundaria para la editorial on-line de Santillana: profes.net. Ha publicado un manual sobre "Métodos de observación aplicados a las Ciencias Sociales y la Educación" dirigido a alumnos de Magisterio.

\section{RESUMEN}

En esta disertación se pretende reflexionar sobre los dilemas éticos entorno a los robots planteados con una proyección al estilo futurista de Julio Verne en el largometraje spielbergiano A.I. Inteligencia Artificial. 


\title{
PALABRAS CLAVE
}

Robot - Inteligencia Artificial - Steven Spielberg - Afectividad - Ética

\begin{abstract}
This paper offers some thoughts about the ethical dilemmas about robots in a Jules Verne-like projection in the spielbergian film "AI Artificial Intelligence".
\end{abstract}

\section{KEY WORDS}

Robot - Artificial Intelligence - Steven Spielberg - Emotions - Ethics

\section{TEXTO}

\section{Introducción}

El proyecto inicial sobre inteligencia artificial de los años 50 pretendía emular el sistema cognitivo humano de modo maximalista en un proyecto de investigación de científicos reunidos durante dos meses.

La realidad científica actual después de más de cincuenta años ha logrado algunos objetivos minimalistas. El ejemplo actual de moda es el robot de la Sony "Asimo" (véase la foto más abajo). Es capaz de andar como un hombre con visión sobre lo que pisa. Existen otros como los robots-niñera que son capaces de desplazarse, vigilar con cámara al niño y grabar recados entre madre e hijo. Hay otros ordenadores con contestaciones inteligentes que hasta bromean. 


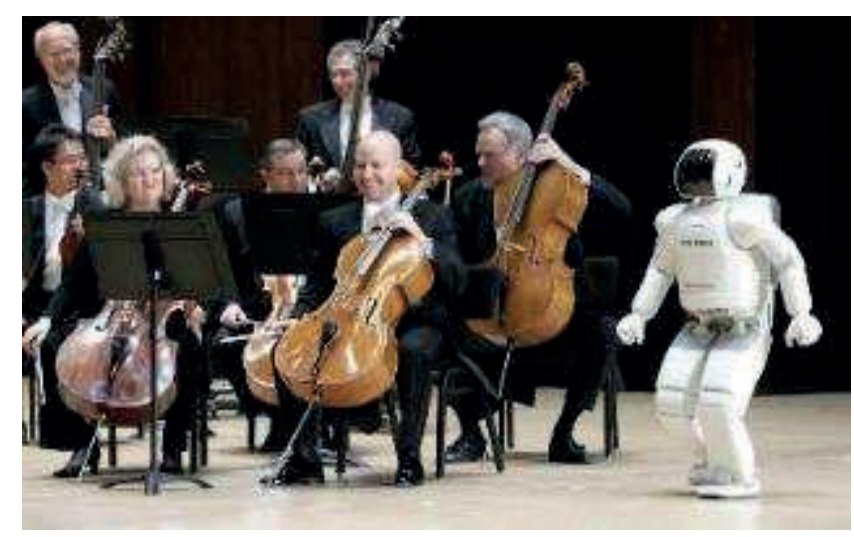

Sin embargo, la pretensión científica maximalista choca con la imposibilidad de reproducir las emociones, la conciencia, la sinápsis y la autoconciencia reflexiva. Se plantea un misterio para los ingenieros informáticos que no saben cómo reproducirlo.

\section{$\underline{\text { Los robots diseñados con "capacidad afectiva" }}$}

El debate ético que interesa plantear es la experimentación actual dirigida a conseguir robots con capacidad afectiva. Se pueden imitar las emociones humanas, los gestos, las respuestas. Este tema está reproducido en una película A.I, Inteligencia Artificial del 2001 con guión y dirección de Steven Spielberg. Este director ha vuelto a ser noticia otra vez por la entrega cuarta de la saga de "Indiana Jones" y por la producción ejecutiva de Transformers (Michael Bay, 2009).

El planteamiento de este director en primer lugar estudia las consecuencias en el caso de que se lograra a través de un personaje robot, David. En segundo lugar, el cineasta plantea la duda de que sea moral crearlos, pues se juega con la cualidad humana de amar.

La originalidad del director norteamericano estriba en que el primer dilema lo plantea mediante la víctima de las consecuencias tecnológicas: el mismo robot que no 
es robot, ni es humano, que está predeterminado a amar a su madre por la que ha sido programado, y por conseguir este amor tiene aspiraciones de llegar a convertirse en un ser auténticamente humano. De modo mágico y fantasioso lo acaba consiguiendo tal y como sucede en el cuento de Pinocho.

El pequeño robot es la víctima por varias razones en la narración fílmica. Para empezar está programado para amar a su madre, no se le programa con libertad para hacerlo o no. La madre decide adoptarlo porque su hijo biológico tiene una enfermedad grave y está crionizado esperando que se encuentre el remedio científico. El pequeño robot entonces pretende ser correspondido por su madre y halagarla en todo instante.

El problema viene cuando el hijo biológico crionizado se cura y vuelve a casa. El hijo biológico comienza a maltratar y rivalizar con el robot, hasta el punto de que lo hace parecer violento y peligroso. Los padres deciden deshacerse del robot, David, pero Mónica, la madre, se compadece y lo abandona en el bosque.

Aquí comienza la aventura llena de peligros para David. En el bosque se encuentra a otros robots que han sido abandonados por roturas, etc., y que son perseguidos por una banda. Ésta los lleva a un espectáculo llamado la Feria de la Carne donde los destrozan y mutilan alimentando el odio de los humanos hacia los robots. David está a punto de ser ejecutado, pero se salva y es acompañado por uno de ellos, un robot gigoló (Joe Gigoló) en un viaje en busca del Hada Azul. Viajan después a Rouge City y de ahí a Manhattan. Allí David conoce al profesor Hobby, su diseñador que le descubre que es un robot y que es el primero de su serie. Hobby le dice que ha desarrollado capacidad humana de perseguir sueños, que está humanizado. Esto es el mayor dolor para David conocer que no es único, ni especial porque sospecha que no consigue así el amor de su madre. Entra en crisis y se suicida dejándose caer al vacío. Cae en el mar y entonces descubre la estatua del Hada Azul. Baja en una nave 
otra vez a rogarle su deseo de ser un niño de verdad, y se queda atrapado durante mucho tiempo hasta que lo rescatan unos robots del futuro. Estos robots conceden a David el deseo de vivir con Mónica un día. El robot este día vive feliz otra vez con Mónica y acaba muriendo junto a ella.

Además existen otras consecuencias que hacen que los robots sufran. Por un lado los humanos comienzan a odiarlos porque son perfectos, más numerosos y más inteligentes. Esto es debido a que el contexto del futuro es un poco desolador en este filme: los humanos son pocos, están obligados a seguir un plan de control de natalidad estatal porque quedan pocos centros urbanos por el deshielo de los polos y la hecatombe ecológica. Por tanto, los robots debido a sus cualidades sufren en ese momento xenofobia social. Por otro lado, este estado ha hecho que los robots desarrollen conciencia de grupo, incluso un sentido de superioridad y que además sean sensibles a la persecución y que sean solidarios entre sí. Por último, el mayor factor de consternación es que tienen un estado ontológico muy cruel, es decir, no tienen una naturaleza plenamente humana. Los últimos robots añoran con melancolía a los humanos que están extintos, y sienten nostalgia de llegar a ser verdaderamente humanos.

\section{$\underline{\text { Los robots que aman, ¿otro tipo de esclavitud? }}$}

El segundo dilema es experimentar con la cualidad de amar al crear un robot con capacidad afectiva. Como hemos dicho con anterioridad, David está predeterminado a amar a su madre Mónica, en este caso se debe en esclavitud a amarla, no puede no amarla o dejar de amarla, o dicho de otro modo, carece de libre albedrío.

Otro aspecto problemático que se plantea es la cuestión de la correspondencia de amor de la familia respecto al robot que se descubre reflejada en la difícil convivencia. En cuanto se producen problemas con David los padres deciden 
rechazarlo, no le corresponden de la misma manera que si fuera humano. El robot se acepta en el hogar como algo útil, que cubre una necesidad, que en este caso es afectiva.

\section{$\underline{\text { Reflexión final: soledad humana y deshumanización }}$}

Este segundo dilema sobre la creación de un robot que llene las necesidades afectivas se entronca con un tema actual planteado por las nuevas tecnologías y la realidad virtual. El tema consiste en que en nuestra sociedad cada vez más tiene lugar la soledad humana. Las causas son diversas: debido a familias desestructuradas, a que los ancianos prefieren vivir solos o no está atendidos, y otros valores sociales en alza como el individualismo, y otras muchas más razones.

El individuo suple esta soledad en ocasiones con una comunicación no directa y comprometida mediante chats, foros, diversión con radio, videojuegos, televisión y cine que pueden acompañar todo el día, etc. Por tanto, si hay soledad humana, o si la necesidad de compañía es real en la sociedad, ¿no vendrían los robots afectivos a cubrir esta necesidad? La respuesta sería: efectivamente sí. Habría empresas interesadas en crearlos y clientes que los comprarían para adquirir esa novedad tecnológica.

La pega que puede tener esto más allá del planteamiento spielbergiano es que a su vez puede ser un motivo de deshumanización para la sociedad. O dicho de otra manera, lo que de verdad comunica y conforta al ser humano es otro ser humano y su contacto con él. El amor se presenta como imprescindible para la naturaleza, por lo tanto, los otros medios indirectos de comunicación o seres robóticos sólo pueden emplearse como medida supletoria, pero nunca pueden sustituir a la persona. Quizás plantear esto es ciencia ficción hoy por hoy, pero tiempo al tiempo... 